\title{
Design and Manufacturing of Laminated Spring: A New Approach Based On Composites
}

\author{
Rohit Ghosh $^{\# 1}$, Sushovan Ghosh ${ }^{\# 2}$,Tanuj Srivastava ${ }^{\# 3}$, \\ Dr.Rabindra Nath Barman ${ }^{\# 4}$ \\ ${ }^{\# 1,2}$ B.Tech student, ${ }^{\# 3}$ M.Tech student, ${ }^{\# 4}$ Assistant Professor, \\ Department of Mechanical Engineering, \\ National Institute of Technology Durgapur, Durgapur, West Bengal, India, Pin-713209 \\ ${ }^{\# 1}$ rohit.99.2016.nitdgpr@gmail.com, ${ }^{\# 2}$ sushovanghoshnitdgp@gmail.com \\ \#3 tanujsrivastava28@gmail.com, ${ }^{\# 4}$ rahul.barman@yahoo.co.in
}

\begin{abstract}
A laminated spring or a leaf spring, being one of the overriding components of an automobile suspension system is nowadays, considered to be a potential factor for reducing vehicle weight. With the advent of composite materials, it has been possible to reduce the weight of the leaf spring without any reduction in the load carrying capacity and stiffness. Composites are well suited for leaf spring applications due to their high strength to weight ratio, fatigue resistance and natural frequency. The achievement of weight reduction with apposite improvement of mechanical properties has made composites an excellent replacement for conventional steels.

The present work is an endeavour to provide the readers as well as the industry with an exclusive construction technique regardingcomposite leaf springs based on an experimental affirmation. Apart from that, the present work converges itself towards the comparative study of steels and composites for the bending stress evaluation and distribution associated with two different categories of leaves in the new construction method based on the rule of mixtures; which again has been one of the parts of the recent developments cognated with the composite leaf springs. The laminated spring was modeled in CATIA V5R18 and the same were analyzed under similar conditions using ANSYS (Workbench 16.2) software considering Structural-Steel and Carbon fiber Steel as the spring material for respective studies. Finally, software based results are presented and compared for two distinct cases mentioned above.
\end{abstract}

Key words: Laminated spring;CATIA V5R18;ANSYS (Workbench 16.2);Carbon fiber steel.

\section{INTRODUCTION}

A spring is an elastic machine element which undergoes deflection for the application of any load and intends to regain its original shape depending upon the magnitude of the applied load. The majorapplications of spring may include its use as a shock and vibration absorber and storing potential energy byits deflection during the application of load. A multi-leaf spring or laminated spring is a very importantcomponent in automobile suspension system. It is one of the oldest suspension components too and stilltoday it is extensively used in all the heavy and light duty commercial vehicles, railway wagons andusually in the rear suspension of passenger vehicles. It differs from the conventional helical spring in a waythat it can be guided along a definite path and it deflects under the application of load while acting as astructural member. This concept is employed during the analysis of bending stresses in different leaves byconsideration of cantilever beam [1-2]. The present work makes an attempt to validate the above concept byperforming static structural analysis using ANSYS software for the evaluation of maximum bending stressand subsequently bending stresses in different leaves, which in all, construct the entire spring. Finally, thereader may get an exposure regarding the bending stress variations for the multi-leaf spring for both the cases associated with steels and composites, which obviouslydiffers from that of any cantilever beam section.

In its construction the leaf spring consists of a series of flat plates or leaves, usually of semi-ellipticshape, which are held together with the help of U-bolts and centre clip. Generally two types of leaves maybe observed in a multi-leaf spring i.e. some graduated -length leaves and a few extra full-length leaves. Thelength of the leaves gradually decreases from top to bottom. The longest leaf in the top is known as masterleaf which is bent at both the ends to form spring eyes. The extra full-length leaves are inserted betweenthe master leaf and the graduatedlength leaves to support the transverse shear force. In order to maintainproper alignment and to restrict the lateral shifting of leaves, rebound clips are used [3]. In practice, thesesprings rest on the axle of an automobile. Its front end is connected with the frame by means of a simplepin joint and the rear end is connected with the frame through a flexible link (known as shackle) [4].

A number of research studies have been carried out in this context to replace the conventional materials of the leafspring by composites to enhance its load carrying capability and to reduce the overall weight of an 
automobile. A composite material can be defined as an amalgamation of two or more materials that results in better properties than those of the individual components used alone. In contrast to metallic alloys, each material retains its separatechemical, physical, and mechanical properties. The two constituents are a reinforcement and a matrix. The main advantages of composite materials are their high strength and stiffness, combined with low density, when compared with bulk materials, allowing for a weight reduction in the finished part. The reinforcing phase provides the strength and stiffness. In most cases, the reinforcement is harder, stronger, and stiffer than the matrix [5]. M.Venkatesan et al., [6] in their work, have shown the design and experimental analysis of a compositeleaf spring made of glass fiber reinforced polymer and compared to steel spring, $67.35 \%$ lesser stress and76.4\% weight reduction were found for the composite spring. K.K.Jadhao et al., [7]in their investigation considered glass fiber reinforced plastic (GFRP) and the polyester resin (NETPOL 1011) as the springmaterial and almost a reduction of $85 \%$ in weight was found after performing numerical and finite elementanalysis for the same. Mr. V. Lakshmi Narayana [8] proclaimed in her study regarding design and analysis of mono composite leaf spring for suspension in automobiles by using ProE \& Ansys that the composite leaf spring weighed only $27.96 \%$ of the steel leaf spring for the analyzed stresses.

Sethilkumar Mouleeswaran [9] performed design and experimental analysis of composite multi leafspring using glass fibre reinforced polymer and the composite leaf spring is found to have $67.35 \%$ lesser stress, $64.95 \%$ higher stiffness and $126.98 \%$ higher natural frequency than that of existing steel leaf spring. The conventional multi leaf spring weighs about $13.5 \mathrm{~kg}$ whereas the E-glass/Epoxy multi leaf spring weighs only $4.3 \mathrm{~kg}$. Thus the weight reduction of $68.15 \%$ is achieved. S.Venkatesh et al.,[10] research work describes about thedevelopment of porous Aluminium foam for makingcommercial vehicle leaf spring made of Aluminium. TheAluminium foamed leaf spring has stresses much lower thansteel leaf spring and weight of aluminium foamed leaf spring was reduced upto $20 \%$ using FEA stress and deflection analysis.M. M. Patunkar et al.,[11] described that under the samestatic loading conditions, deflection and stresses of steel leaf spring and composite spring are foundto have a greatdifference indicating reduction in weight by $84.40 \%$ under the same level ofperformance.M. Raghavedra et al., [12] performed design and analysis of laminated composite mono leaf spring. Compared to mono steel leaf spring the laminated composite mono leaf spring have $47 \%$ lesser stresses, $25 \% \sim 65 \%$ higher stiffness, $27 \% \sim 67 \%$ higher frequency and weight reduction of $73 \% \sim 80 \%$.Y.N.V. Santhosh Kumar et al., [13] in their work observedthat the composite leaf spring weighed only $39.4 \%$ of the steelleaf spring for the analyzed stresses. Hence the weightreduction obtained by using composite leaf spring ascompared to steel was $60.48 \%$.Hence, surely composite materials may be able to provide a better performance andefficiency in the practical applications but, from manufacturing point of view we must admit that they aremore expensive than that of steel. That's why extending the research work performed by Rohit Ghosh et al., [1] the present exertion completely dismisses the propositionassociated with manufacturing the complete spring by composites; but maintains its intense focus to manufacture those parts which are relatively more stressed as well as to maintain conventional materials for the lesser stressed parts to achieve an optimum extent towards the manufacturing costs. In the present work, the full-length leaves of a multi-leaf spring, which exhibit more stresses, were modelled separately with composites apart from the graduated length leaves where conventional steel is maintained and the entire system is combinedly analysed by using proper contact constraints under similar conditions in ANSYS software.

\section{MATHEMATICAL FORMULATIONS}

For the purpose of analysis, the leaves are divided in two groups as master leaf along with graduatedlengthleaves forming one group and the extra full-length leaves forming the other group.

Let,

$\mathrm{n}_{\mathrm{f}}=$ number of extra full-length leaves,

$\mathrm{n}_{\mathrm{g}}=$ number of graduated-length leaves including the master leaf,

$\mathrm{n}=\mathrm{n}_{\mathrm{f}}+\mathrm{n}_{\mathrm{g}}=$ Total number of leaves present in the multi-leaf spring,

$\mathrm{b}=$ width of each leaf $(\mathrm{mm})$,

$\mathrm{t}=$ thickness of each leaf $(\mathrm{mm})$,

$\mathrm{L}=$ half the length of the semi-elliptic spring or the length of the cantilever $(\mathrm{mm})$,

$\mathrm{P}=$ force applied at the end of the spring $(\mathrm{N})$,

$\mathrm{P}_{\mathrm{f}}=$ portion of $\mathrm{P}$ taken by the extra full-length leaves $(\mathrm{N})$,

$\mathrm{P}_{\mathrm{g}}=$ portion of $\mathrm{P}$ taken by the graduated-length leaves $(\mathrm{N})$,

So, $\mathrm{P}=\mathrm{P}_{\mathrm{f}}+\mathrm{P}_{\mathrm{g}}$

Now, from practical considerations for an automobile leaf spring, that is of semi-elliptical shapeusually, for a length of $2 \mathrm{~L}$ and a load of $2 \mathrm{P}$ acting at the centre, the entire beam can be considered as adouble cantilever. If the leaves are cut into two equal halves in longitudinal plane and then combinedaccordingly, to form almost a triangular plate then,

The maximum bending stress is given by [14-15]. 
$\left(\mathrm{s}_{\mathrm{b}}\right)_{\max }=\frac{\text { 6.P.L }}{\text { n.b.t } \mathrm{t}^{2}}$

The bending stress in the graduated-length leaves is given by [3]

$\left(\mathrm{s}_{\mathrm{b}}\right)_{\mathrm{g}}=\frac{12 \cdot \mathrm{P} \cdot \mathrm{L}}{3 \cdot \mathrm{n}_{\mathrm{f}}+2 \cdot \mathrm{n}_{\mathrm{g}}}$

The bending stress in the extra full-length leaves is given by [3]

$\left(\mathrm{s}_{\mathrm{b}}\right)_{\mathrm{f}}=\frac{18 \cdot \mathrm{P} \cdot \mathrm{L}}{3 \cdot \mathrm{n}_{\mathrm{f}}+2 \cdot \mathrm{n}_{\mathrm{g}}}$

The maximum deflection of the spring is given by [3]

$\delta=\frac{12 \cdot P \cdot L^{3}}{\text { E. }\left(3 . n_{\mathrm{f}}+2 \cdot n_{\mathrm{g}}\right) \cdot \mathrm{b} \cdot \mathrm{t}^{3}}$

It is to be noted that, the maximum bending stress occurs at the supports for such a plate. The aboverelations hold good for the leaves (or plates), having uniform cross-section. Also, it is seen that the bendingstresses in extra full-length leaves are $50 \%$ more than that of the graduated length leaves i.e. $\left(\mathrm{s}_{\mathrm{b}}\right)_{\mathrm{f}}=1.5\left(\mathrm{~s}_{\mathrm{b}}\right)_{\mathrm{g}}[3]$.

Calculation of length of different leaves:

For the calculation of length of different leaves, following relations were used and subsequently, theresults were implemented while modeling the multi-leaf spring in CATIA V5R18 software.

Length of the smallest leaf $=1 * \frac{\text { Effective length }}{\mathrm{n}-1}+$ Ineffective length

Length of the next leaf $=2 * \frac{\text { Effective length }}{\mathrm{n}-1}+$ Ineffective length

Similarly, Length of the $(\mathrm{n}-1)$ th leaf $=(\mathrm{n}-1) * \frac{\text { Effective length }}{\mathrm{n}-1}+$ Ineffective length

Length of master leaf $=2 . L+2$. P. $(d+t)$

Ineffective length $=$ Distance between the centres of U-bolts $=1$, Effective length $=2 \cdot \mathrm{L}-2 \cdot \frac{1}{3}$ and $\mathrm{d}=$ inside diameter of eye [2].

Apart from the above formulations, when a unidirectional continuous-fiber lamina or laminate is loaded in a direction parallel to its fibers $\left(0^{\circ}\right.$ or 11-direction),the longitudinal modulus $\mathrm{E}_{11}$ can be estimatedfrom its constituent properties by using what isknown as the rule of mixtures [5]: $\mathrm{E}_{11}=\mathrm{E}_{\mathrm{f}} \mathrm{V}_{\mathrm{f}}+\mathrm{E}_{\mathrm{m}} \mathrm{V}_{\mathrm{m}}$,

whereo $_{\mathrm{f}}$ is the fiber modulus, $\mathrm{V}_{\mathrm{f}}$ is the fiber volume percentage, $\mathrm{E}_{\mathrm{m}}$ is the matrix modulus, and is the matrix volume percentage.

The longitudinal tensile strength $\mathrm{s}_{11}$ also canbe estimated by the rule of mixtures [5]: $\mathrm{s}_{11}=\mathrm{s}_{\mathrm{f}} \mathrm{V}_{\mathrm{f}}+\mathrm{s}_{\mathrm{m}} \mathrm{V}_{\mathrm{m}}$, Where $s_{\mathrm{f}}$ and $\mathrm{s}_{\mathrm{m}}$ are the ultimate fiber and matrix strengths, respectively. Because the properties of the fiber dominate for all practical volumepercentages, the values of the matrix can often be ignored. So, the rule of mixtures has formed the basis for composite analysis during the simulation of the extra full-length leaves; which were again combinedly examined in the software with the graduated leaves made of steelas a single unit.

\section{DESIGN SPECIFICATION}

The objective of the present course of study includes, determination of maximum bending stress for threedifferent loading conditions for both the cases of steels and composites and to establish the relationship for the magnitude of bending stresses existingin the graduated-length leaves and extra full-length leaves (i.e. $\left(\mathrm{s}_{\mathrm{b}}\right)_{\mathrm{f}}=$ $\left.1.5\left(\mathrm{~s}_{\mathrm{b}}\right)_{\mathrm{g}}\right)$, with the followingdimensional specifications,

Table I :Specification of laminated spring

\begin{tabular}{|c|c|c|}
\hline Parameters & Value & Notation \\
\hline Total length of the semi-elliptic spring (distance between two eyes ) & $1243 \mathrm{~mm}$ & $2 \mathrm{~L}$ \\
\hline width of each leaf & $100 \mathrm{~mm}$ & $\mathrm{~B}$ \\
\hline thickness of each leaf & $14 \mathrm{~mm}$ & $\mathrm{~T}$ \\
\hline number of extra full-length leaves & 2 & $\mathrm{n}_{\mathrm{f}}$ \\
\hline number of graduated-length leaves including the master leaf & 8 & $\mathrm{n}_{\mathrm{g}}$ \\
\hline Total number of leaves present in the multi-leaf spring & 10 & $\mathrm{~N}$ \\
\hline Load acting at the centre of the spring & $\begin{array}{c}15000 \mathrm{~N}, 10000 \\
\mathrm{~N}, 5000 \mathrm{~N}\end{array}$ & $2 \mathrm{P}$ \\
\hline
\end{tabular}


The dimensions are taken from practical understanding and the standards available in the market.For the first case, Structural steel was considered as the entire leaf material with an elastic modulus $\mathrm{E}=2.1 * 10^{5} \mathrm{MPa}$, tensile yield strength $\mathrm{S}_{\mathrm{yt}}=250 \mathrm{MPa}$ and Poisson's ratio=0.3 while performing the analysis in ANSYS(Workbench 16.2) software. In the next case, Carbon fiber steel has been considered as the material for the full-length leaves (fiber lamina or laminate is loaded in a direction parallel to its fibers) whereas, material for the rest of the leaves were kept same i.e. structural steel. For Carbon fiber steel, an Elastic Modulus E $=2.64 * 10^{5} \mathrm{MPa}$ and ultimate strength $\mathrm{S}_{\mathrm{ut}}=540 \mathrm{MPa}$ (at dry room temperature) were considered for simulation purpose; determined on the basis on rule of mixtures.

\section{ANALYTICAL CALCULATION}

From the relation of maximum bending stress $\left(\mathrm{s}_{\mathrm{b}}\right)_{\max }$ and based on the above design specifications, the analytical calculation is carried out for the load of $15000 \mathrm{~N}$.

From equation (1) the maximum bending stress is given by,

$\left(\mathrm{s}_{\mathrm{b}}\right)_{\max }=\frac{6 . \mathrm{PL}}{\text { n.b.t }{ }^{2}}$

We have, $2 \mathrm{P}=15000 \mathrm{~N}, 2 \mathrm{~L}=1243 \mathrm{~mm}, \mathrm{n}=10, \mathrm{~b}=100, \mathrm{t}=14 \mathrm{~mm}$, then

$\left(\mathrm{s}_{\mathrm{b}}\right)_{\max }=\left\{6^{*}(15000 / 2) *(1243 / 2)\right\} /(10 * 100 * 142)=142.691 \mathrm{MPa}$

Subsequently, the maximum bending stresses were evaluated for the loads of $10000 \mathrm{~N}, 5000 \mathrm{~N}$ andpresented in Table: II.For the composite analysis part, as we know, when a unidirectional continuous-fiber lamina or laminate is loaded in a direction parallel to its fibers $\left(0^{\circ}\right.$ or 11 -direction $)$, the longitudinal modulus $\mathrm{E}_{11}$ can be estimatedfrom its constituent properties by using what isknown as the rule of mixtures [5]: $\mathrm{E}_{11}=\mathrm{E}_{\mathrm{f}} \mathrm{V}_{\mathrm{f}}+$ $\mathrm{E}_{\mathrm{m}} \mathrm{V}_{\mathrm{m}}$

Where $E_{f}$ is the fiber modulus, $V_{f}$ is the fiber volume percentage, $E_{m}$ is the matrix modulus, and $V_{m}$ is the matrix volume percentage. The longitudinal tensile strength $\mathrm{s}_{11}$ also canbe estimated by the rule of mixtures: $\mathrm{s}_{11}=$ $\mathrm{s}_{\mathrm{f}} \mathrm{V}_{\mathrm{f}}+\mathrm{s}_{\mathrm{m}} \mathrm{V}_{\mathrm{m}}$, where $\mathrm{s}_{\mathrm{f}}$ and $\mathrm{s}_{\mathrm{m}}$ are the ultimate fiber and matrix strengths, respectively.

Considering, $\mathrm{V}_{\mathrm{f} .}=0.6, \mathrm{~V}_{\mathrm{m}}=0.4, \mathrm{E}_{\mathrm{f}}=3.0^{*} 10^{5} \mathrm{MPa}, \mathrm{E}_{\mathrm{m}}=2.1 * 10^{5} \mathrm{MPa}, \mathrm{s}_{\mathrm{f}}=600 \mathrm{MPa}, \mathrm{s}_{\mathrm{m}}=450 \mathrm{MPa}[20-21]$

We get, $\mathrm{E}_{11}=\mathrm{E}_{\mathrm{f}} \mathrm{V}_{\mathrm{f}}+\mathrm{E}_{\mathrm{m}} \mathrm{V}_{\mathrm{m}}=0.6 * 3.0^{*} 10^{5}+0.4 * 2.1 * 10^{5}=2.64 * 10^{5} \mathrm{MPa}$

$\mathrm{s}_{11}=\mathrm{s}_{\mathrm{f}} \mathrm{V}_{\mathrm{f}}+\mathrm{s}_{\mathrm{m}} \mathrm{V}_{\mathrm{m}}=0.6 * 600+0.4 * 450=540 \mathrm{MPa}$

\section{MODELLING and SIMULATION}

The objective of this analysis is to investigate the stresses in the laminated spring within the desirablelimits to obtain a practical understanding for the theoretical ideas associated with composite materials. After geometric modeling in CATIAV5R18 software the spring is subjected to static analysis, performed in ANSYS (Workbench 16.2)software.

\section{A. Modelling}

The computer compatible mathematical description of the geometry of the object is called geometric modeling. CATIA is basically CAD (computer-aided design) software that allows themathematical description of the object to be displayed and manipulated as the image on the monitor of thecomputer [16-17]. While modelling the spring, the full length leaves were designed separately as a different part body shown in Fig. 1, 2, 3 ; which were again combined with rest of the leaves in Ansys software through proper contact constraints.

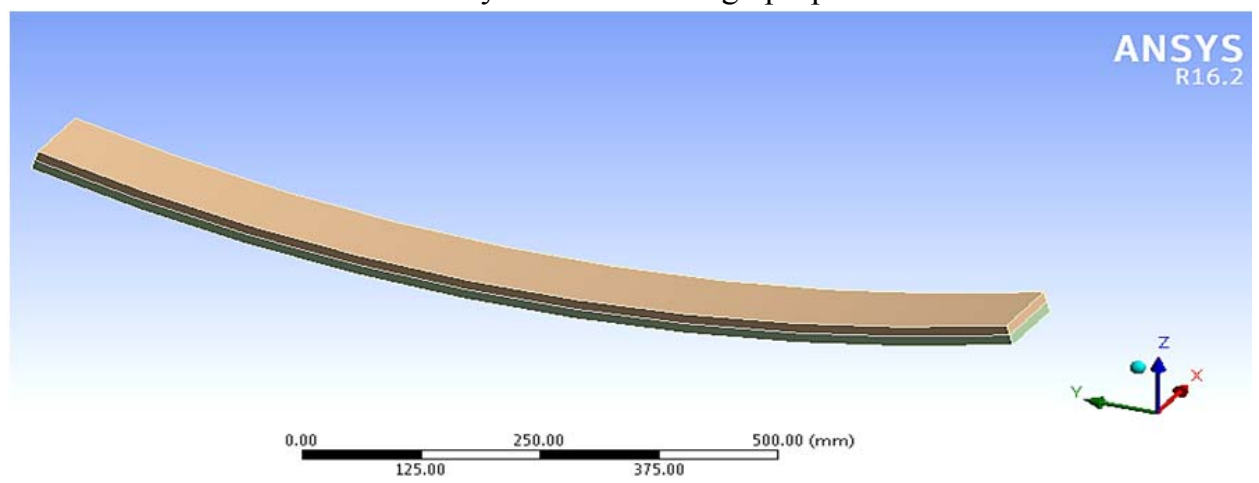

Fig. 1. Extra-full length leaves modelled separately 


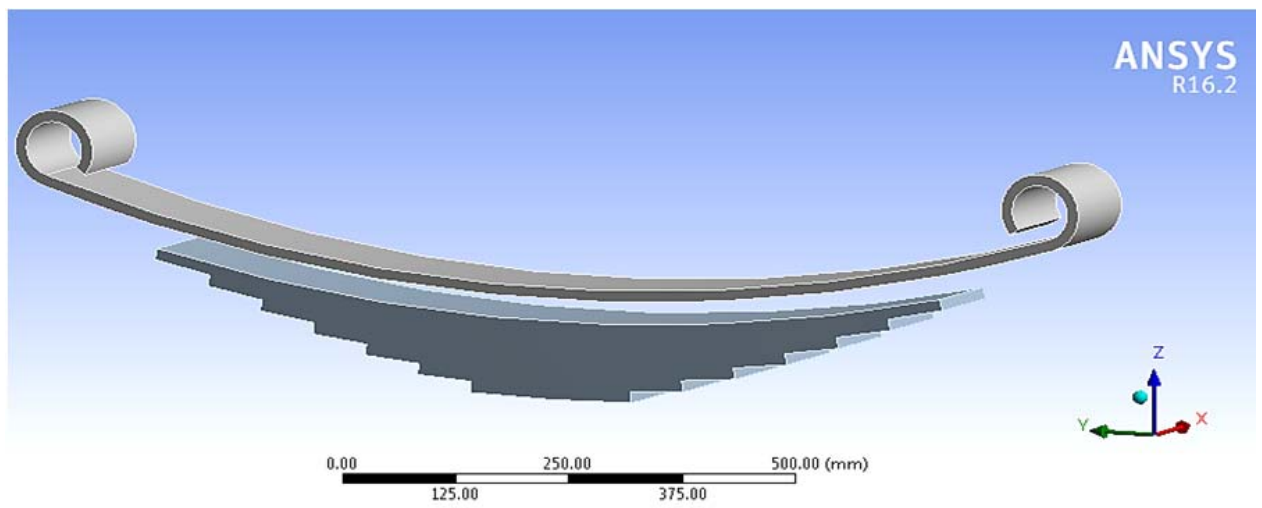

Fig. 2. Graduated length leaves modelled separately

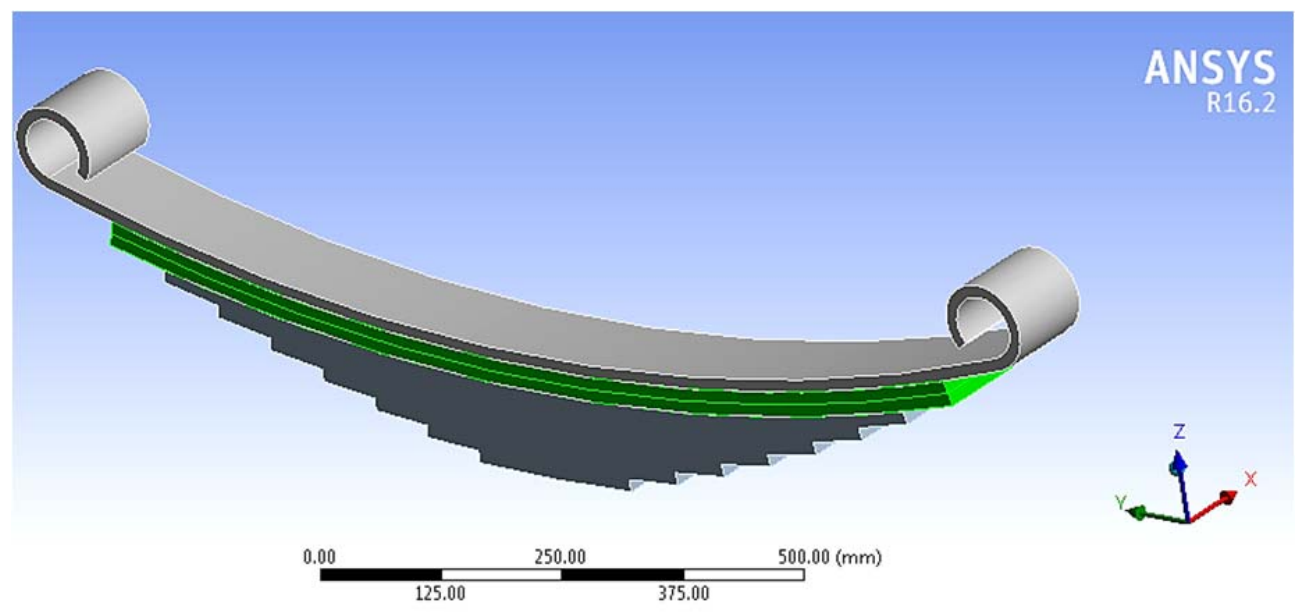

Fig. 3. Complete assembly of the laminated spring

ANSYS is an engineering simulation software that predicts with confidence aboutthe performance of the product under the real-world environments incorporating all the existing physicalphenomena [18-19]. While performing the part of composite analysis, the composite properties were imposed only in these full-length leaves by incorporating the new value of elastic modulusobtained from the rule of mixtures. The layout of static analysis involves meshing, boundary conditions and loading.

\section{B.Meshing}

Meshing is basically the division of the entire model into small elements. In order to maintain the shape, it is convenient to select the free mesh, as the geometry of leaf spring contains sharp curves. Element size of $20 \mathrm{~mm}$ with medium smoothing was considered for mesh generation. Minimum edge length of the elements was $14 \mathrm{~mm}$. Within the solution domain under the Adaptive Mesh Refinement segment, Max. Refinement Loops was taken as 3 and Refinement Depth as 2. For the convergence plot, the maximum allowable change was considered as $4 \%$. All the 44 faces were selected for mesh generation and totalnumber of nodes and elements were observed as 13423 and 7358 respectively. Fig. 4 shows the meshedmodel of laminated spring. 


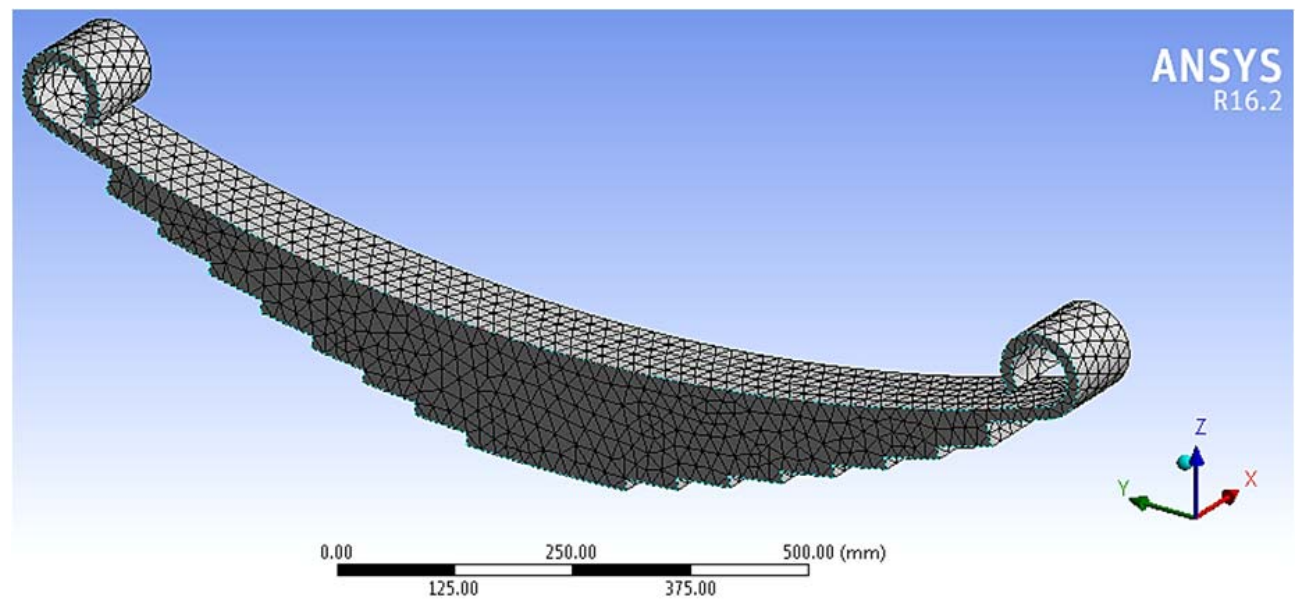

Fig. 4. Meshed model of the laminated spring

\section{Boundary Conditions}

The leaf spring is mounted on the axle of an automobile. The frame of the vehicle is connected to the endsof the leaf spring. The ends are constructed in such a way that they form an eye like structure. The fronteye of the spring is directly connected with the frame by means of a simple pin joint; hence, it can freelyrotate about the pin but is restricted for any kind of translation and rotation in all the other directions. Sounder the static structural domain of ANSYS software, the Remote Displacement was inserted and exceptrotation about X- axis, all other motions were constrained to set the above boundary condition. Now, therear eye of the leaf spring is connected with the frame through a flexible link known as shackle. So, it hasthe flexibility to slide along length of the spring and also to rotate about the pin. These were againestablished through Remote Displacement by setting Y- direction as unconstrained for translationaccording to the geometry, while keeping all other translator y motions restricted and rotation about Xaxiswas set free as before, keeping all other rotational motions constrained for the rear eye of the spring.

\section{Load}

The load is uniformly distributed by all the nodes associated with the bottom surface of the bottommost leaf. The Load is applied along $\mathrm{F}_{Z}$ direction as shown in Fig. 5. To apply the load, under the staticstructural domain of ANSYS Software, Force was introduced and the magnitude of load was given for Zdirection.Here, we have considered a load of $5000 \mathrm{~N}$ is acting on the bottom most leaf.

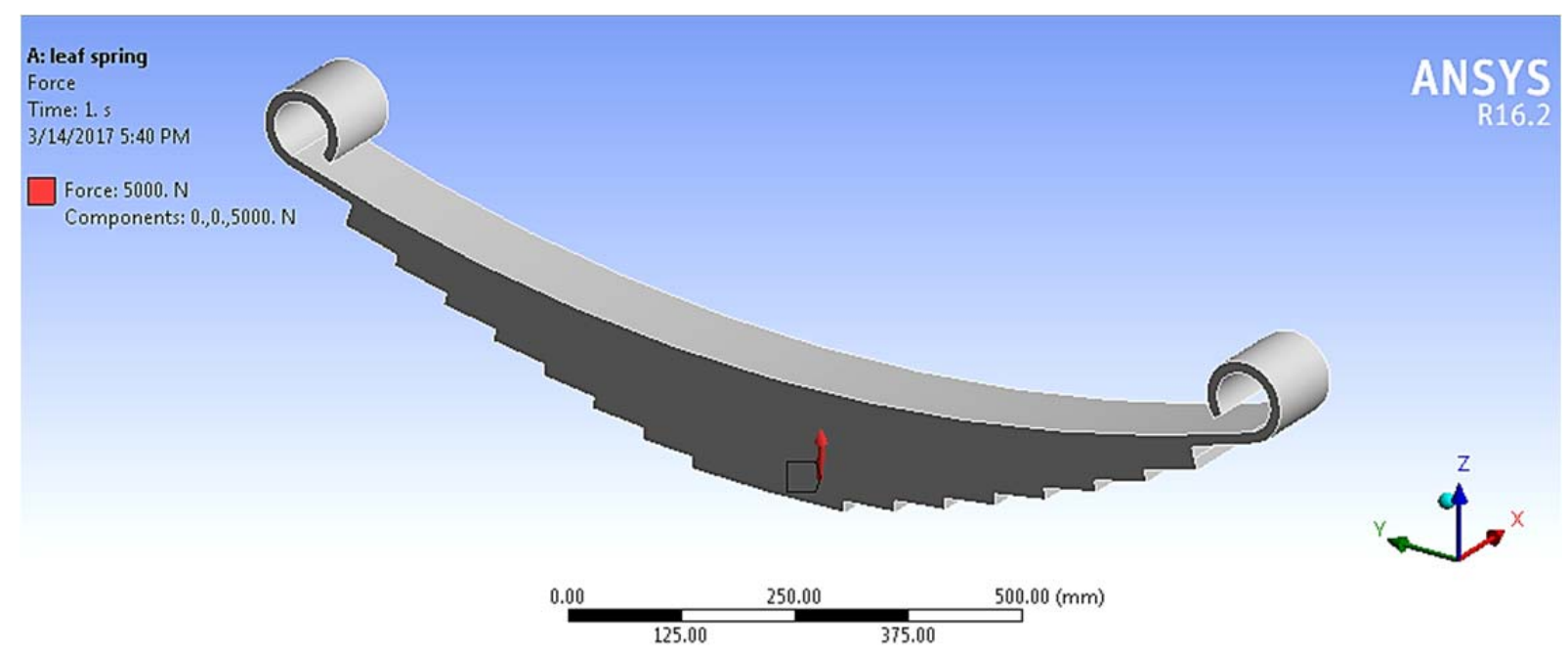

Fig. 5. Loading (5000 N) of the laminated spring 


\section{RESULTS and DISCUSSIONS}

After performing the static analysis for both the cases of structural Steel and Carbon Fiber Steel for given dimensional specifications, the results obtained are summarised as follows:

\section{A. Weight reduction:}

Apart from the other benefits, the biggest benefit, however, is mass reduction for using composite materials for the full-length leaves. While, the mass for the laminated spring assembly was $89.447 \mathrm{~kg}$ before applying composites; for the next case on application of the same for full-length leaves, reduced the mass to $79.99 \mathrm{~kg}$. So, almost a reduction of $10 \mathrm{~kg}$ can be obtained with the new construction method which can provide a great help towards the modern automobile industry that is increasingly focussing on weight reduction.

\section{B. Maximum equivalent (von-Mises) stress:}

Simulations were carried out for the three different loading conditions and the results obtained were similar in nature indicating a comprehensible trend towards the decreasing value of maximum equivalent (von-Mises) stress for composite applications. The experimental results obtained are conveyed as follows:

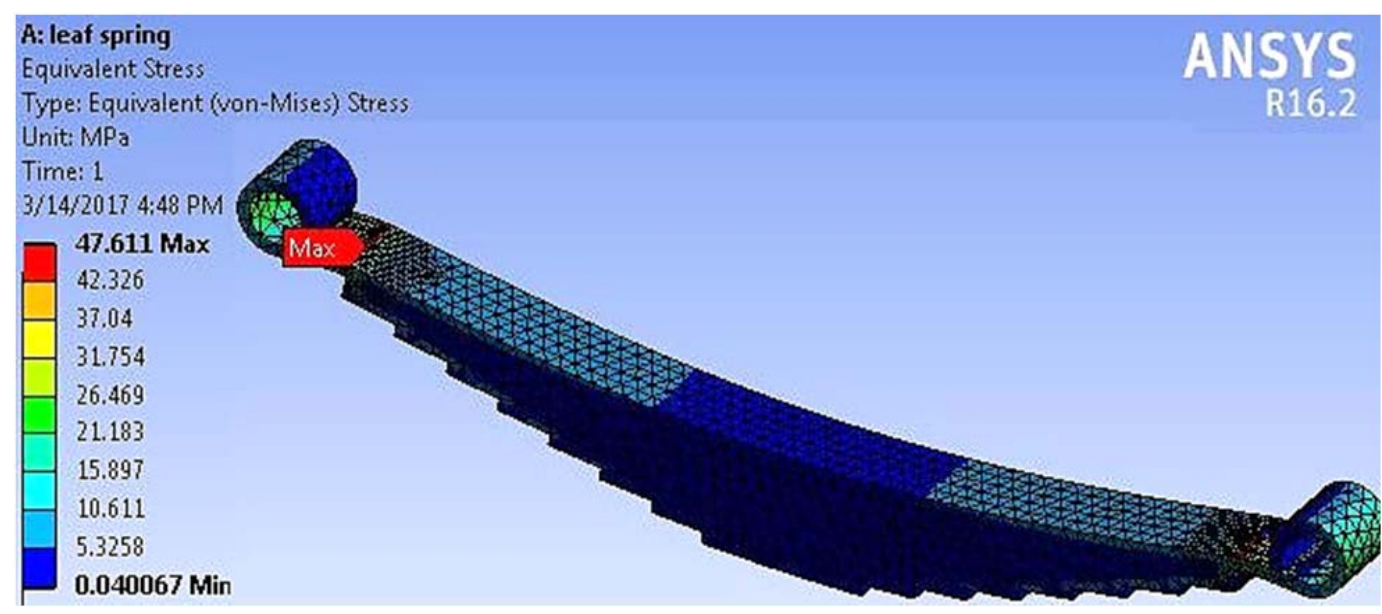

Fig. 6. Distribution of equivalent (von-Mises) stresses at a load of $5000 \mathrm{~N}$ for structural steel

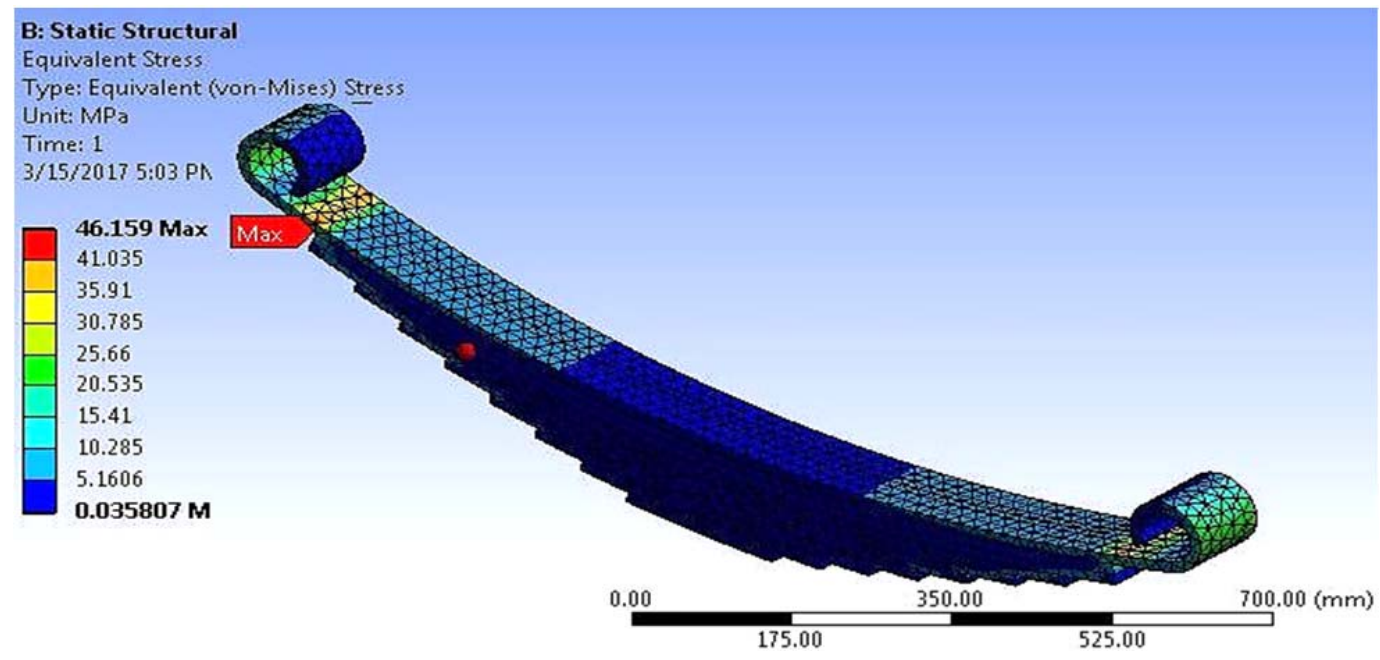

Fig. 7. Distribution of equivalent (von-Mises) stresses at a load of $5000 \mathrm{~N}$ for composite applications 
ISSN (Print) : 2319-8613

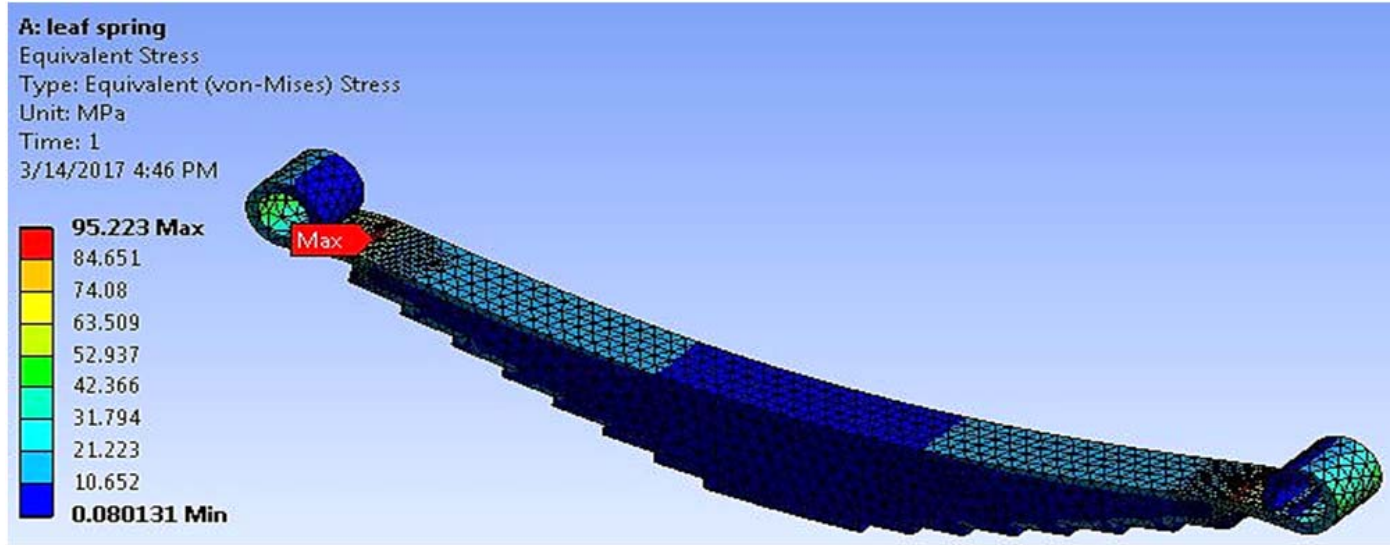

Fig. 8. Distribution of equivalent (von-Mises) stresses at a load of $10000 \mathrm{~N}$ for structural steel

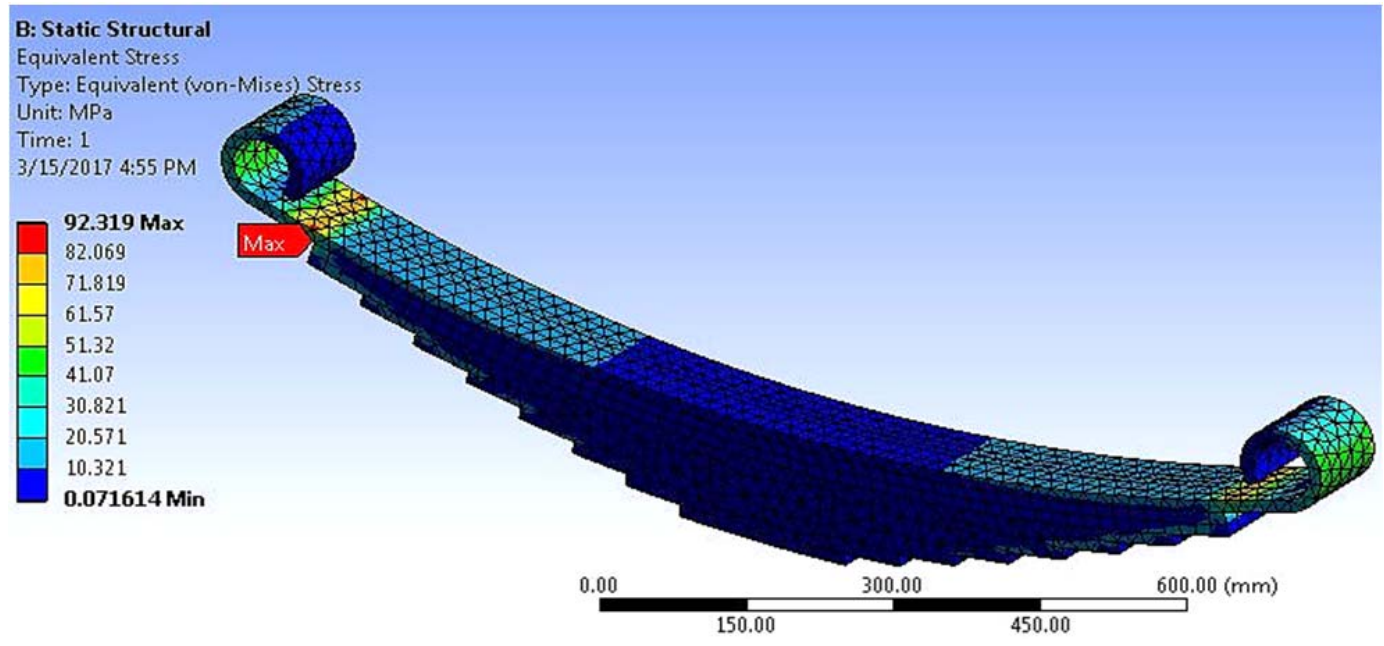

Fig. 9. Distribution of equivalent (von-Mises) stresses at a load of $10000 \mathrm{~N}$ for composite applications

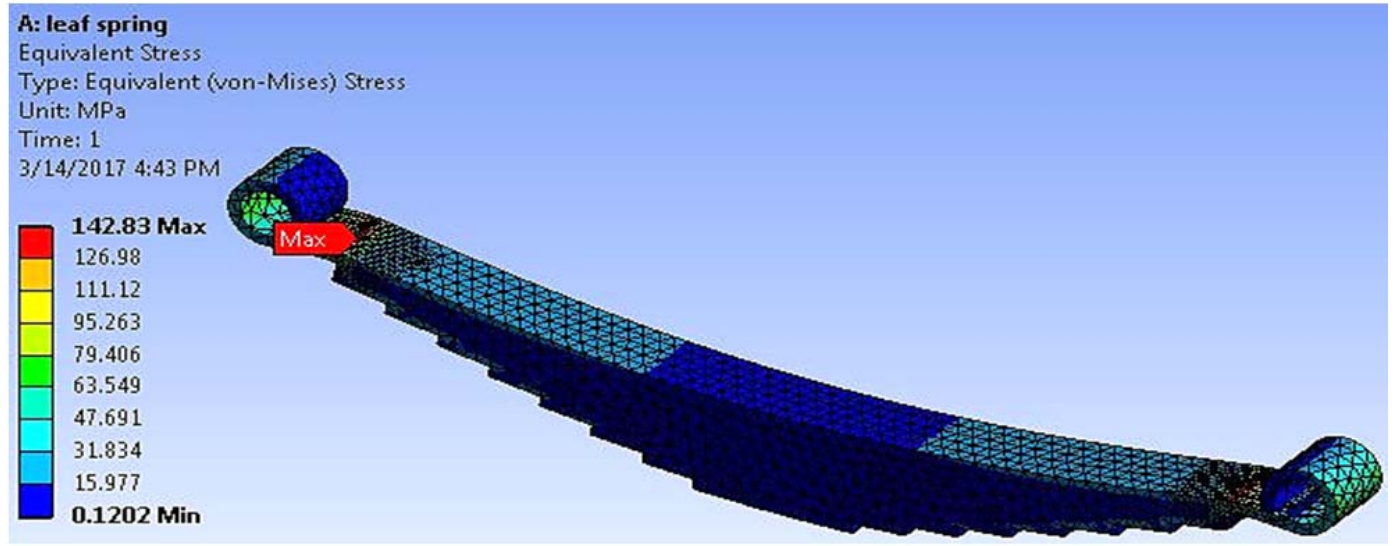

Fig. 10. Distribution of equivalent (von-Mises) stresses at a load of $15000 \mathrm{~N}$ for structural steel 


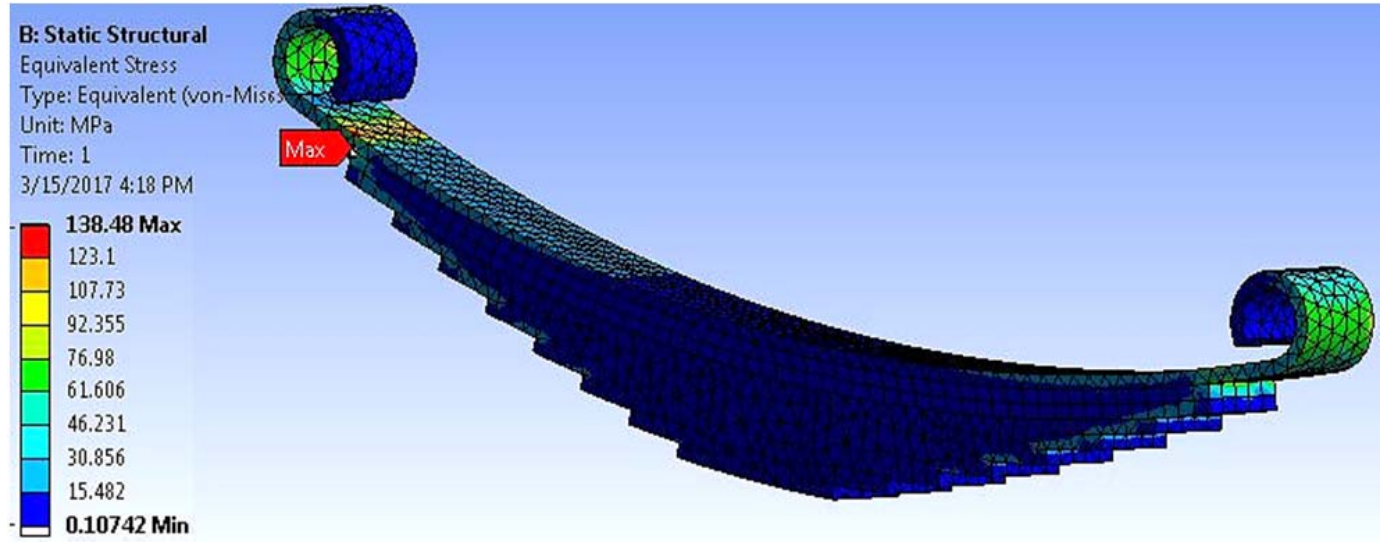

Fig. 11. Distribution of equivalent (von-Mises) stresses at a load of $15000 \mathrm{~N}$ for composite applications

A graph is plotted for the conventional steel and Composite based results with load on $\mathrm{X}$-axis and stress values onY-axis, shown in the following Fig. 12. There is a clear tendency towards stress reduction for the application of carbon fiber in the full length leaves.

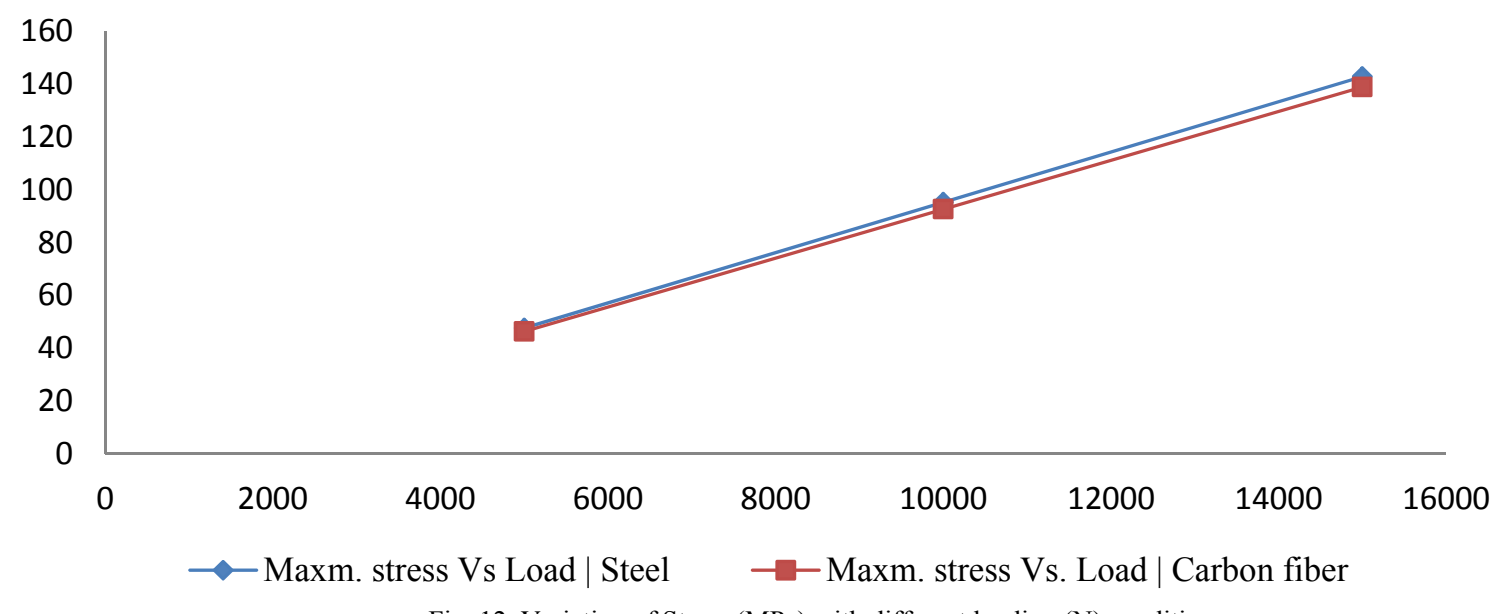

Fig. 12. Variation of Stress (MPa) with different loading $(\mathrm{N})$ conditions

The software based analysis was performed for the three different loading conditions and the results obtained were similar in nature indicating a comprehensible trend towards the decreasing value of Directional deformation for composite applications. The experimental results obtained are conveyed as follows:

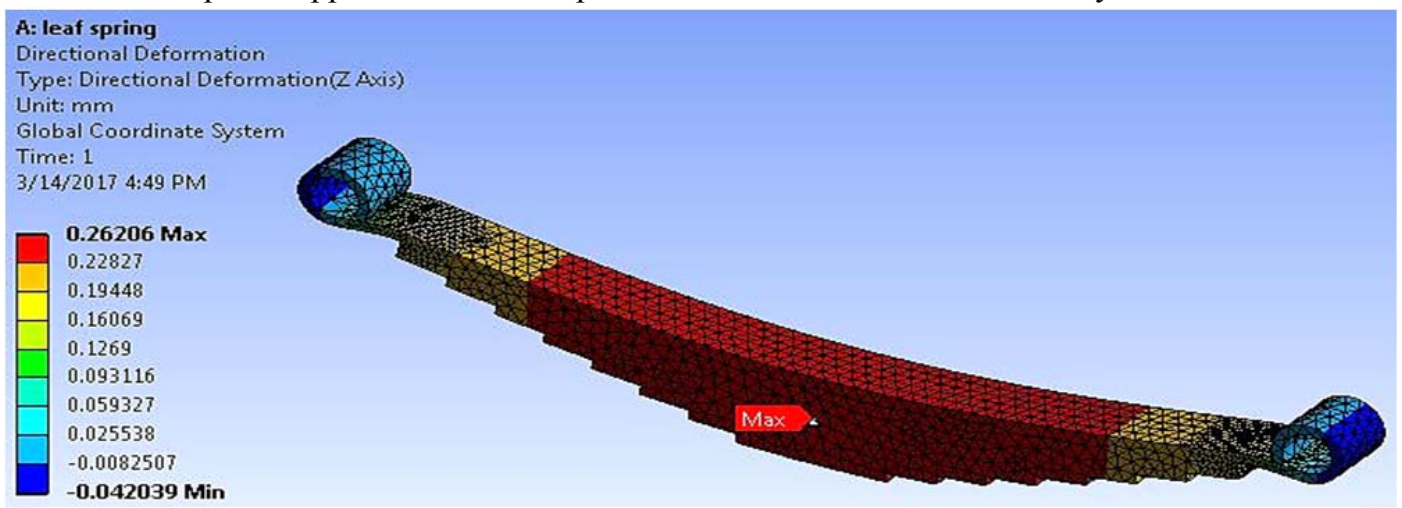

Fig. 13. Distribution of directional deformation at a load of $5000 \mathrm{~N}$ for structural steel 
ISSN (Print) : 2319-8613
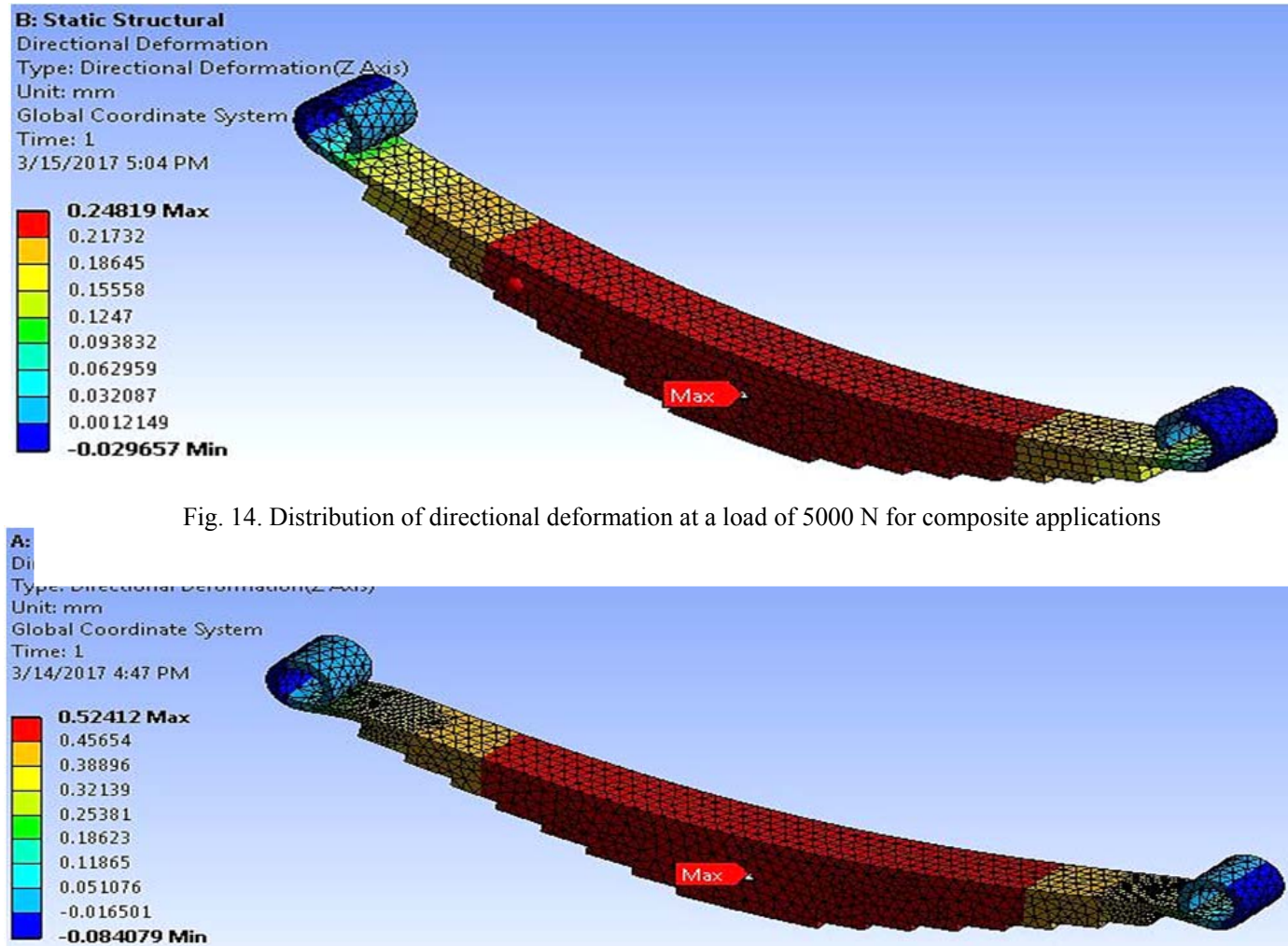

Fig. 15. Distribution of directional deformation at a load of $10000 \mathrm{~N}$ for structural steel

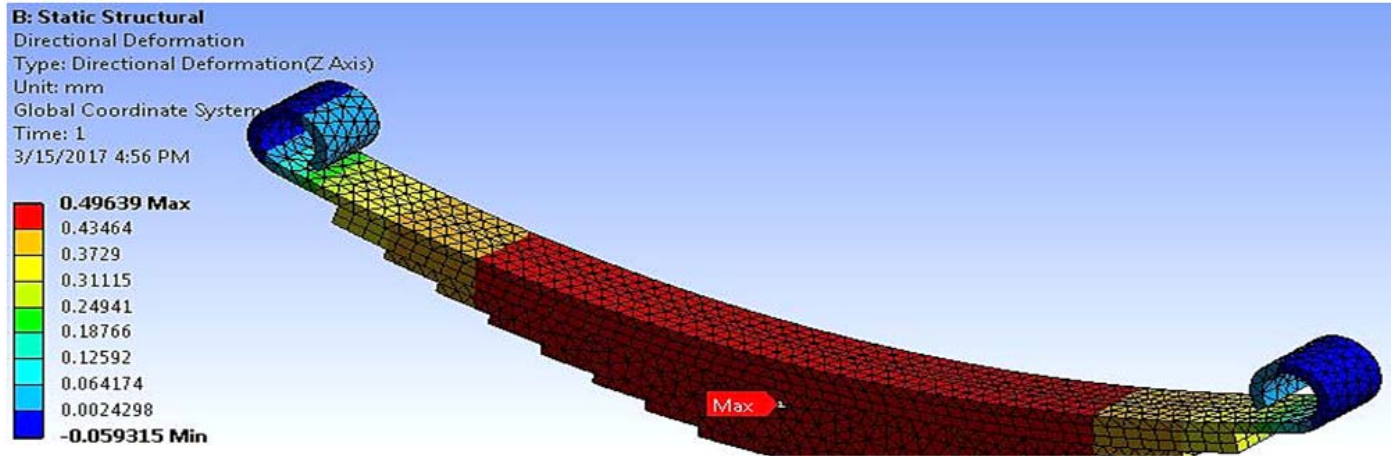

Fig. 16. Distribution of directional deformation at a load of $10000 \mathrm{~N}$ for composite applications

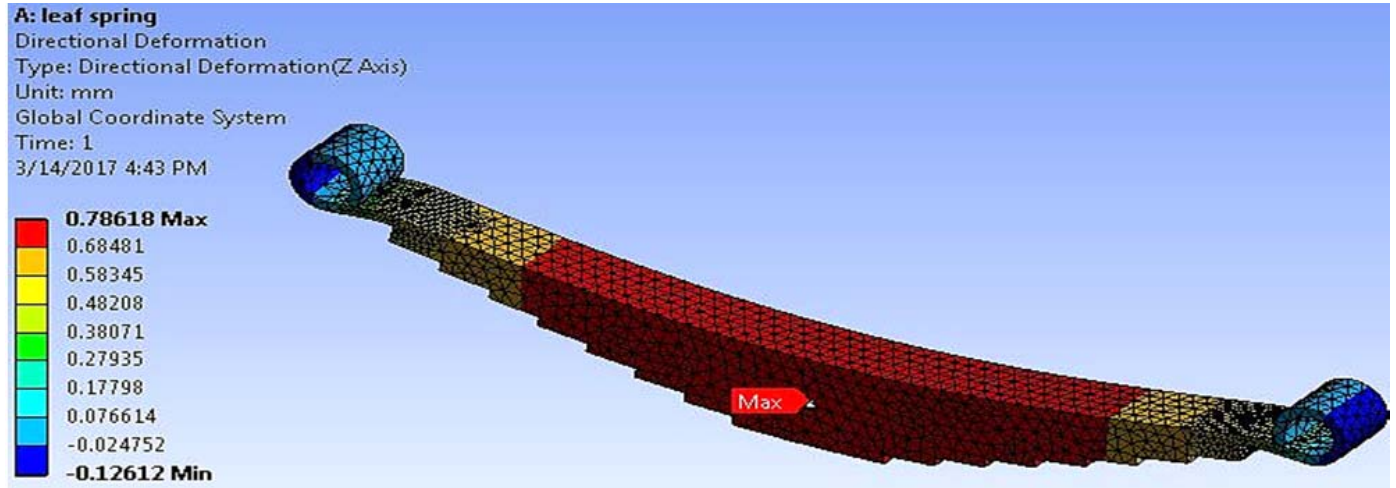

Fig. 17. Distribution of directional deformation at a load of $15000 \mathrm{~N}$ for structural steel 


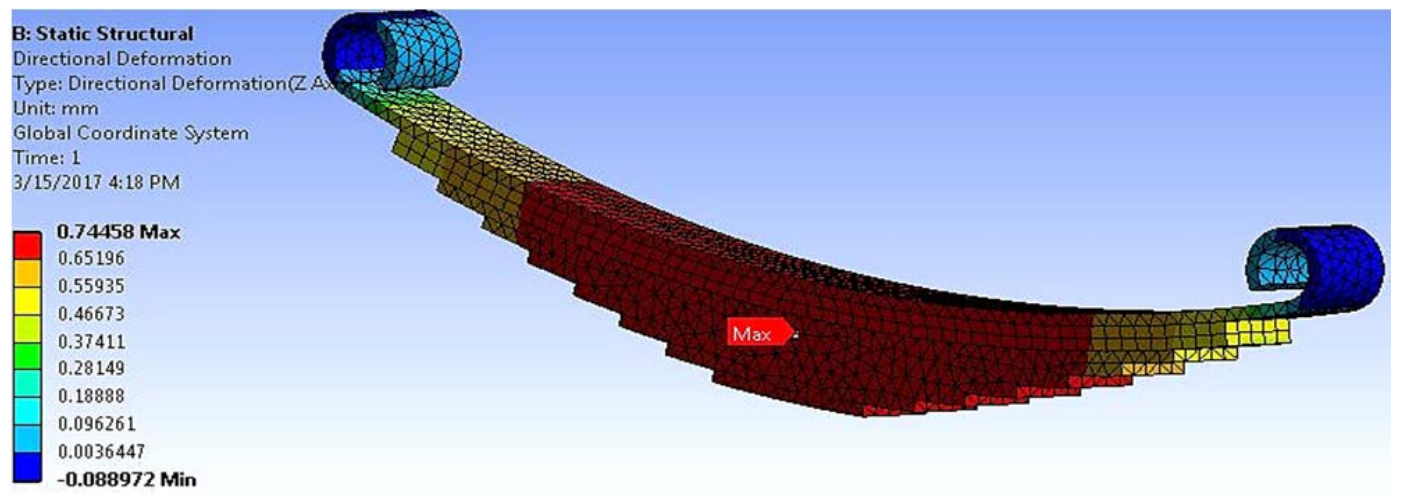

Fig. 18. Distribution of directional deformation at a load of $15000 \mathrm{~N}$ for composite applications

A graph is plotted for the conventional steels and Composite based results with load on $\mathrm{X}$-axis and directional deformation values onY-axis, shown in the following Fig. 19. There is a clear tendency towards the reduction of directional deformation for the application of carbon fiber in the full length leaves.

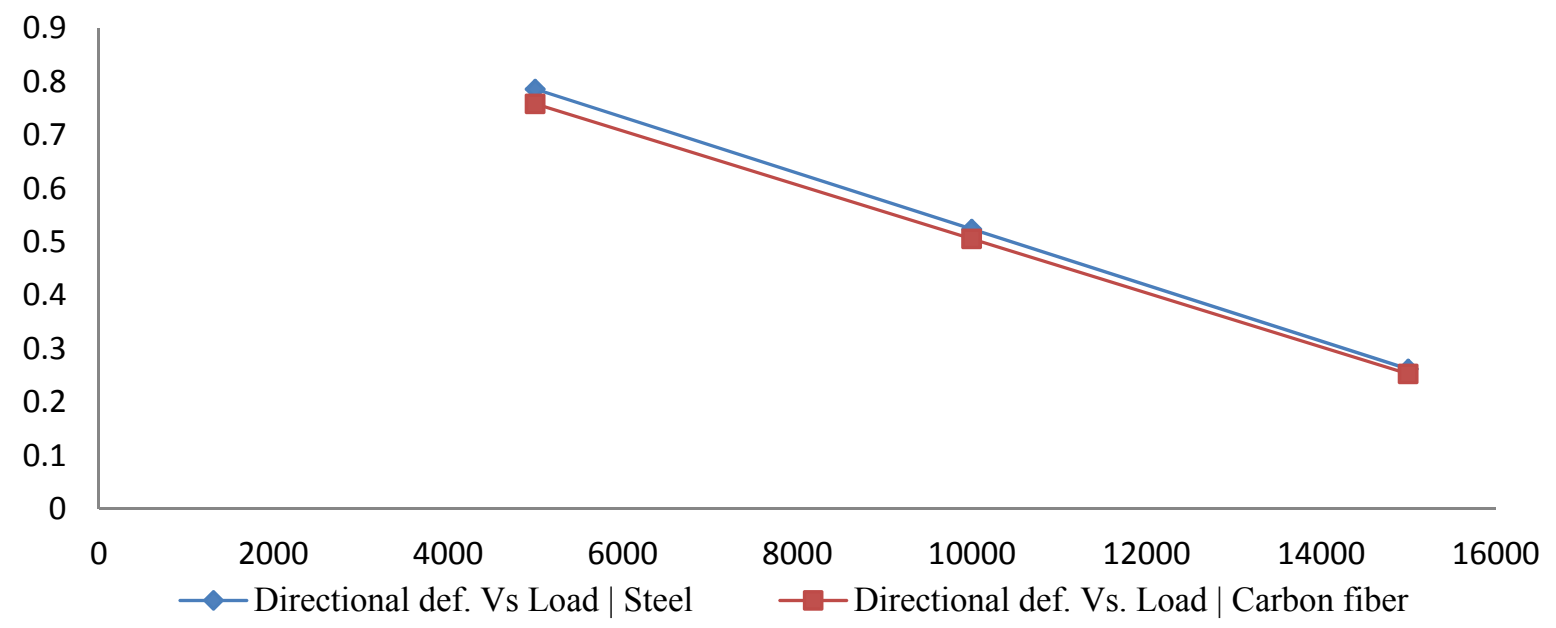

Fig. 19. Variation of directional deformation (mm) with different loading $(\mathrm{N})$ conditions

\section{D.Bending Stress distribution across the leaves:}

In order to demonstrate the variation of bending stresses in different leaves at a particularload, we will take the help of the following Fig. 20.Using the Probe feature of ANSYS software, the stresses 7.578, 0.55374 and 3.9708(in MPa) in three different locations at a particular cross-section are shown in the Fig. 20. For a load of $15000 \mathrm{~N}$ for structural steels.It can be clearly observed that, the stress value of 7.578, (MPa) associated with the extra full- length leaves are almost more than 1.5 times than that of the stress value of 3.9708 (MPa) corresponding to the graduated length leaves; and both the locations are almost equidistant from the minimum stress value point ( 0.55374$)$ as shown. So, the nature of the result confirms the fact that, in contrast to uniform linear distribution of stress for simply supported beams from the neutral plane here, a nonlinear tendency is been observed due to the presence of full-length leaves exhibiting relatively higher stresses even being at a equal distance from the minimum stress value point. For more accurate positioning the result may approach towards the exact theoretical results; as we know of the stress being 1.5 times in full-length leaves than that of the graduated. 


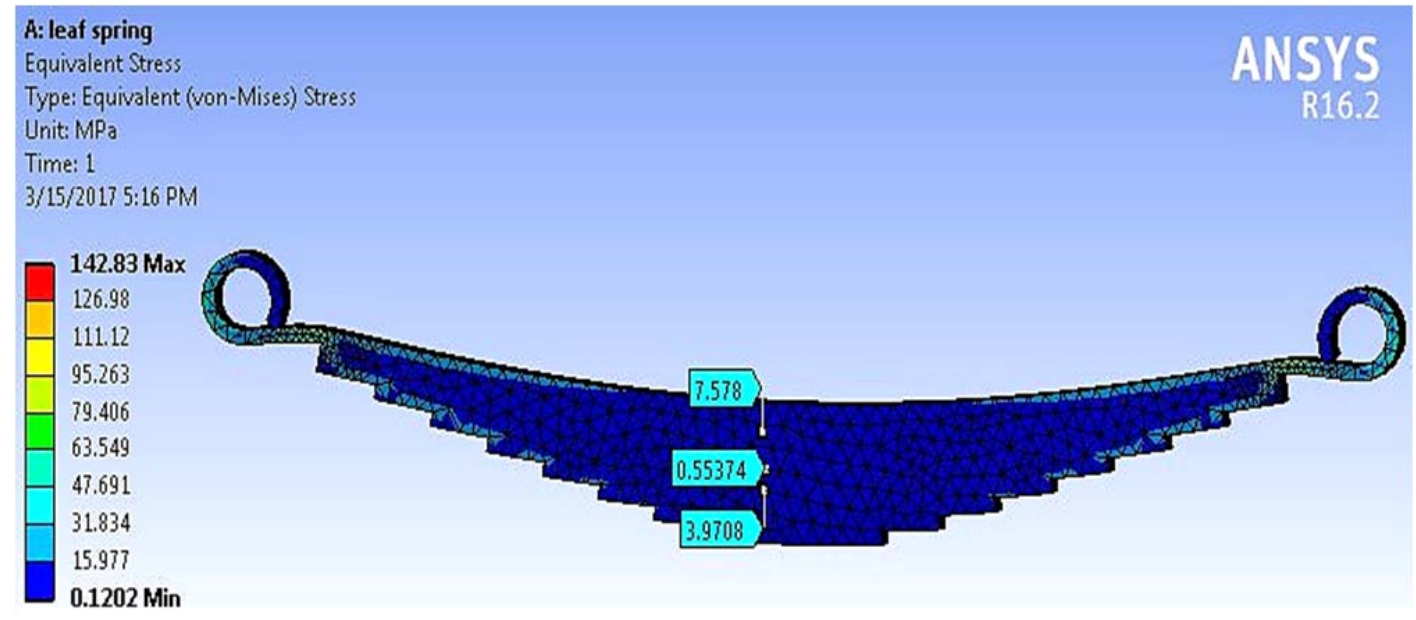

Fig. 20. Distribution of equivalent (von-Mises) stress across a cross section for structural Steel

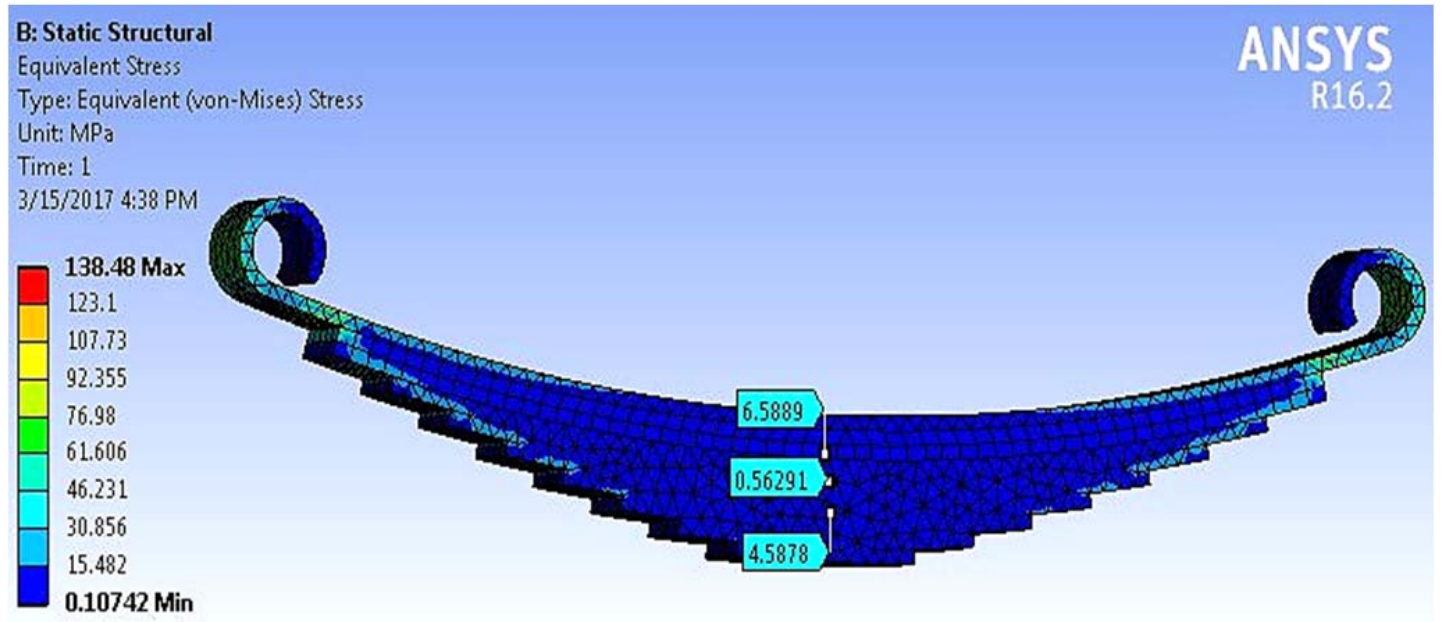

Fig. 21. Distribution of equivalent (von-Mises) stress across a cross section for composite application

Again with the help of Probe tool, the stress values approximately at a particular cross-section have been shown above in Fig. 21. for composite application at a load of $15000 \mathrm{~N}$. The value associated with the extra-full length leaves is 6.5889 (in MPa) and that for graduated leaves is 4.5878 (in MPa) from an equidistant minimum stress value point of 0.56291 (in MPa). So it has been observed that for composite applications, the stresses at fulllength leaves have been reduced significantly from its previous value 7.578 (in $\mathrm{MPa}$ ) associated with conventional steels which confirms our proposal as well as different research works performed earlier.The software based results are summarised as follows: 
Table II : Comparison for steel and composite applications

\begin{tabular}{|c|c|c|c|c|}
\hline \multirow{2}{*}{ Parameter } & Load (in newton) & $\begin{array}{c}\text { Steel application for } \\
\text { the entire spring }\end{array}$ & $\begin{array}{c}\text { Composite application } \\
\text { for full-length leaves } \\
\text { maintaining Steel for } \\
\text { rest of the part }\end{array}$ & \% change reduction \\
\hline \multirow{2}{*}{$\begin{array}{c}\text { Max. Equivalent (von- } \\
\text { Mises) stress (in MPa) }\end{array}$} & 15000 & 142.83 & 138.90 & 2.751523 \\
\cline { 2 - 5 } & 10000 & 95.223 & 92.602 & 2.752486 \\
\hline \multirow{2}{*}{$\begin{array}{c}\text { Directional } \\
\text { deformation (in mm) }\end{array}$} & 15000 & 47.611 & 46.301 & 2.751465 \\
\cline { 2 - 5 } & 10000 & 0.262 & 0.25277 & 3.522901 \\
\hline Mass (in kg) & 5000 & 0.52412 & 0.5055 & 3.552622 \\
\hline
\end{tabular}

\section{CONCLUSION and FUTURE SCOPE of WORK}

In the present work, the laminated spring is modeled in CATIA V5R18 and same were analyzed in the Static structural domain of ANSYS software.The results were discussed in the preceding section and it isconcluded that, for the given design specifications the values of maximum stresses at different loading conditions are well within the safe limits. Apart from that, most crucially the new construction method has proposed to manufacture the full- length leaves separately with composites in contrast to use of composites for the entire spring. From the software based results, we observed a comprehensible decreasing trend toward the stress and deformation values for composite applications. A mass reduction of more than $10 \%$ being the biggest benefit with the new method; we also achieve an optimum extent towards the manufacturing costs as composites being highly expensive [2223] than that of steels (almost 2-3 times costlier). So, the new method seems to be beneficial exclusively for modern auto industry as it provides an optimum solution towards weight reduction as well as manufacturing costs; finally leading towards a level of greater customer satisfaction.

An extended study can be carried out on the topic in the context of different joining methods for metalswith composites if we implement the proposed construction methodology for the spring. Mechanical Fasteners, adhesives or both can be used to join composites [24], but to choose the most effective onerequires an extensive effort for the same. Apart from that, the various factors associated with working conditions need to be considered as well.

\section{REFERENCES}

[1] Rohit Ghosh, Sushovan Ghosh, Shirish Ghimire and Dr.RabindraNath Barman, "Static analysis of multi-leaf spring using ansys workbench 16.0", International Journal of Mechanical Engineering and Technology (IJMET), vol.7, issue 5, 2016, pp. $241-249$.

[2] G. Harinath Gowd, E. Venugopal Goud, "Static analysis of leaf spring", International Journal of Engineering Science and Technology (IJEST), ISSN: 0975-5462 vol. 4 No.08 August 2012.

[3] V.B. Bhandari, Design of Machine Elements, McGraw Hill Education, ISBN: 0-07-0681791-1, 2014.

[4] Preshit. B. Waghmare, Raosaheb. B. Patil, "Static and modal analysis of leaf spring using fea",International Journal of Technical Research and Applications e-ISSN: 2320-8163, vol.3, Jan-Feb 2015.

[5] F.C. Campbell, Structural Composite Materials, Available: http://www.asminternational.org.

[6] M. Venkatesan, D. Helmen. Devaraj (2012), "Design and analysis of composite leaf spring in light Vehicle", International Journal of modern engineering research, vol. 2, pp. 213-218.

[7] K. K. Jadhao, DR. R.S. Dalu, "Experimental investigation \& numerical analysis of composite leaf spring", ISSN: 0975-5462 vol. 3 No. 6 June 2011.

[8] Mr .V. Lakshmi Narayana, "Design and analysis of mono composite leaf spring for suspension in automobiles", International Journal of Engineering Research \&Technology(IJERT) vol. 1, issue.6, August - 2012 ISSN: 2278-0181.

[9] Sethilkumar Mouleeswaran, "Design, manufacturing and testing of polymer composite multi-leaf spring for light passenger automobiles", ISSN 1392-1320 Materials Science (Medžiagotyra). vol. 13, no. 2. 2007.

[10] S. Venkatesh, Dr. S. S. Mohamed Nazirudeen, Dr. A. K.Shaik Dawood, R. Karthikeyan, "Development of porous Aluminium foam for making commercial vehicle leaf spring", IRACST - EngineeringScience and Technology: An International Journal (ESTIJ),ISSN: 2250-3498, vol.2, no. 4, August 2012.

[11] M. M. Patunkar, D. R. Dolas "Modelling and analysis of composite leaf spring under the static load condition by using fea", International Journal of Mechanical \& Industrial Engineering, vol. 1, issue. 1, 2011. 
[12] M. Raghavedra, Syed Altaf Hussain, V. Pandurangadu, K. PalaniKumar, "modeling and analysis of laminated composite leaf spring under the static load condition by using fea", International Journal of Modern Engineering Research (IJMER), vol. 2, issue. 4, JulyAug. 2012 pp-1875-1879 ISSN: 2249-6645.

[13] Y. N. V. Santhosh Kumar \& M. Vimal Teja, "Design and Analysis of Composite Leaf Spring", International Journal of Mechanical and Industrial Engineering (IJMIE), ISSN No. 2231 -6477, vol. 2, issue. 1, 2012.

[14] R.S. Khurmi, J.K. Gupta, A Text Book of Machine Design (S. Chand, Eurasia Publishing House (pvt.) ltd.,2005), India.

[15] Richard G. Budynas and J. Keith Nisbett ,Shigley's Mechanical Engineering Design, 10/e , McGraw Hill Education, ISBN: 0073398209, copyright year: 2015.

[16] Brighthubengineering webpage [Online], Available: http://www.brighthubengineering.com/cad-autocad-reviews-tips/19291applications-of-thecad-software-what-is-geometric-modeling.

[17] Ebook777 webpage [Online], Available: http://www.ebook777.com/catia-v5-6r2014-designers

[18] Ansys webpage [Online], Available: http://www.ansys.com

[19] Caeai webpage [Online], Available: https://caeai.com/ansys-software.../ansys-software/mechanical-simulation-software

[20] Steelforge webpage [Online], Available: www.steelforge.com/literature/metal-tidbits/tensilestrength

$\begin{array}{llll}\text { [21] Performance-composites } & \text { webpage } & \text { [Online], } & \text { Available: }\end{array}$ ht//www. performancecomposites.com//carbonfibre/mechanicalproperties_2.asp

[22] Buildings.com webpage [Online], Available: www.buildings.com/news/industry-news/articleid/14300/title/new-low-e-glassorwindow-film-a-comparison-to-help-you-decide/viewall/true

[23] [Online], Available: www.google.co.in $/$ webhp? sourceid=chrome-instant\&ion=1\&espv=2\&ie=UTF$8 \# q=$ cost $\% 20$ of $\% 20$ steel $\% 20$ per\%20square $\% 20$ foot

[24] Machine design webpage [Online], Available: machinedesign.com/basics-design/joining-composites 